\title{
Quem é o homem aranha: uma análise cultural-midiá- tica da identidade nerd pelo viés dos Estudos Culturais
}

\section{Andréa Corneli Ortis}

Universidade Federal de Santa Maria, Programa de Pós-Graduação em Comunicação, Santa Maria, Rio Grande do Sul, Brasil. Contato com a autora: ortia.andrea@gmail.com

\section{Lucas da Silva Nunes}

Universidade Federal de Santa Maria, Programa de Pós-Graduação em Comunicação, Santa Maria, Rio Grande do Sul, Brasil. Contato com o autor: lucasnunespp@gmail.com

\section{Flavi Ferreira Lisbôa Filho}

Universidade Federal de Santa Maria, Programa de Pós-Graduação em Comunicação, Santa Maria, Rio Grande do Sul, Brasil. Contato com a autora: lucasnunespp@gmail.com 
Resumo: O presente artigo aborda as representações da identidade nerd no filme Homem-Aranha, lançado em 2002. Temos como objetivo central neste trabalho analisar as características do nerd presentes na produção cinematográfica por meio dos conceitos levantados pelos Estudos Culturais, entre eles, cultura, identidades, representações. Para isso, foi feito um recorte na figura do protagonista Peter Parker, interpretado pelo ator Tobey Maguire, seguindo o percurso metodológico do modelo de análise textual de Casetti e Chio (1999). Como principal resultado, temos que o nerd é representado por meio de estereótipos.

Palavras-chave: Estudos Culturais. Identidades. Identidade nerd. Análise textual. Homem-Aranha.

Abstract: This article addresses the representations of the nerd identity in the film Spider-Man, released in 2002. Our main objective is to analyze the characteristics of the nerds present in this cinematography production, through the concepts raised by Cultural Studies, such as culture, identities and representations. Thereto, it has been made a clip in the figure of the protagonist Peter Parker, performed by actor Tobey Maguire, following the methodological lines of Casetti and Chio's textual analysis model (1999). As a main result, we perceive that the nerd is still represented with some stereotypes, especially with regard to class and gender.

Keywords: Cultural studies. Identities. Nerd identity. Textual analysis. Spider Man. 


\section{Introdução}

O presente artigo busca compreender como se dão as representações da identidade nerd no filme Homem-Aranha. Para isso, faz-se um recorte do personagem Peter Parker, interpretado pelo ator Tobbey Maguire, do filme Homem-Aranha, lançado em 2002 e produzido pela Sony Pictures. Esse personagem, desde o seu surgimento no universo das Histórias em Quadrinhos, foi concebido como um adolescente nerd, conforme explicam seus criadores Stan Lee, Jack Kirby e Steve Ditko ${ }^{1}$.

Quanto à contribuição desta investigação para o campo da comunicação, ela está centrada na proposta de compreender as formas de construção da identidade nerd através do personagem Peter Parker. Pretende-se também interpretar e questionar estas características, visto que, muitas vezes, elas contribuem para olhares genéricos sobre esta identidade. Utiliza-se o método de análise textual de Casetti e Chio (1999) com recortes em elementos e características que contribuem para a constituição do personagem, como sua aparência física, gostos pessoais e comportamentos.

\section{A noções de cultura, identidades e representações pelo viés dos Estudos Culturais}

Os Estudos Culturais surgiram no século XX em um contexto social de pós-guerra e reestruturação social. O campo entende os produtos culturais como agentes de reprodução social e construtores da hegemonia que, em síntese, é constituída pelos grupos que estabelecem um modo de vida e um pensamento dominante difundido por toda a sociedade, influenciando e, até mesmo, criando valores, gostos, práticas políticas e relações sociais (KATZ, 2007).

A cultura, a partir dos Estudos Culturais, é conceituada como um importante fator na definição de vida e significados partilhados entre indivíduos. Williams (1992, p. 9) atribui a ela o papel de estabelecer um "bem" comum e influenciar os modos de pensar. Já para Cuche (2002), caracterizá-la é uma tarefa complexa, pois carrega consigo uma série de significados que vão desde a cultura/cultivo de espécies, passando pelos conceitos de adoração a algo, chegando ao consumo de bens artísticos e eruditos, denotando as visões elitistas e restritas do termo. Para esse mesmo autor, o conceito pode também ser encarado como o conjunto de ideologias que norteiam os modos comportamentais e de pensamento.

Aos olhos de Hall (1997), a cultura assume três aspectos: o normativo, que é responsável por guiar as ações humanas; o regulatório, que classifica as ações segundo as normas sociais; e o terceiro aspecto assume a responsabilidade de induzir o sujeito a assimilar e internalizar as condutas vigentes. Seguindo por esta linha de raciocínio e encarando a cultura como algo coletivo, chegamos ao que Williams (1992) chama de ideologia, que define sua "posição

1 Disponível em: $<$ https://omelete.uol.com.br/quadrinhos/artigo/a-criacao-do-homem-aranha/>. Acesso em: 02/12/2017. 
e posicionamento no mundo". Assim, de acordo com a perspectiva dos Estudos Culturais, ela é parte fundamental para a produção de significados em um terreno de lutas e negociações entre os grupos envolvidos (FRANÇA; SIMÕES, 2017).

Pelo fato de as culturas serem encaradas como padrões partilhados que condicionam os modos de agir dos indivíduos, Ortiz (2015) define-as como um software mental que molda as interações pessoais e a formação de grupos sociais. Os grupos sociais, por sua vez, são caracterizados pela união de indivíduos que se conectam entre si por meio de gostos e comportamentos em comum. Estas ligações se dão por meio de identificações que, dentro dos Estudos Culturais, são caracterizadas pelas identidades.

O processo de formação de identidades pode ser entendido pelo conjunto de informações partilhadas entre os indivíduos, sendo elas genéticas, regionais e midiáticas. Estas estabelecem pontos de identificações entre os indivíduos e nos dão a possibilidade de sermos reconhecidos como integrantes de um grupo social (HENRIQUES, 2016). Assim, as identidades são relacionais, ou seja, para Ortiz (2015) necessitamos de um "outro" para nos identificarmos. Elas são utilizadas para afirmar o que somos e o que não somos, demarcando diferenças e apontando semelhanças e exclusões entre os grupos sociais.

No que se refere ao conceito de representação, para Jodelet (2002), em um ponto de vista sociológico, contribui para a formação de uma realidade comum por meio de aspectos imagéticos, mentais e sociais aliados à cognição e comunicação. A autora enfatiza o papel dos agentes produtores e aborda o campo da representação social como um campo de produção de significados sobre alguém ou alguma coisa.

Assim, a ideia de representação está fundamentada em nossas vivências bem como em nossa visão de mundo que temos de determinadas pessoas ou objetos. Desse modo, a representação é uma prática cultural, “um tipo de 'trabalho' que lança mão de objetos materiais e produz efeitos sobre os sujeitos" (ZUBARAN et al 2016, p. 17). Para Mazzotti (2002, p. 19), “as representações podem ser vistas como uma visão funcional do mundo, que permite ao sujeito dar sentido a sua conduta e compreender a realidade através de seu próprio sistema de referências e, portanto, adaptar-se, definir seu lugar". Nesse sentido, podemos compreender a representação como uma ideia em comum sobre algo determinado ou, ainda, como "a conexão entre conceitos e linguagem que permite nos referirmos ao mundo 'real' dos objetos, sujeitos ou acontecimentos, ou ao mundo imaginário de objetos, sujeitos e acontecimentos fictícios" (HALL, 2016, p. 34).

Além disso, a representação é fruto dos modos como a linguagem presente nos meios de comunicação é capaz de alterar as imagens e significados que temos de nós mesmos e dos outros (HALL, 1997). Ela atua como forma regulatória de nossos valores e condutas através de códigos culturais e signos disseminados na sociedade.

Diante das teorias abordadas até agora, percebe-se que não devemos separá-las, pois cultura, identidades e representações estão interligadas, já que elas fornecem o material necessário para que as pessoas moldem suas identificações (KELLNER, 2001). Sendo assim, as 
representações midiáticas são importantes elementos forjadores de identidades e em busca de verificar estas correlações, o presente artigo aborda a identidade nerd e sua representação.

\section{Quem são os nerds?}

Vivemos em uma sociedade plural, composta por diversos povos e culturas. Fazendo um recorte de determinada cultura, podemos citar os indivíduos pertencentes ao grupo denominado nerd. Hall (2006) traz ainda como exemplo as identidades nacionais, nas quais se reúnem os integrantes de determinado grupo cultural de acordo com local de origem, genética e o passado em comum. Porém, esse grupo, por não ser oriundo de um mesmo espaço geográfico, une-se em torno do que é apresentado na mídia e de acordo com seus comportamentos, incluindo também seus hábitos de consumo. Como lembra Santos (2014, p. 15), "cultura nerd, como se configura nos dias de hoje, é construída com base na expertise tecnológica e no consumo midiático, fatores fundamentais da formação da identidade pessoal e cultural dos nerds". Devido ao alto consumo midiático dos membros desta cultura e por ela reproduzir significados sobre eles, faz-se necessária uma análise sobre como essa tribo está sendo representada. Ainda, por ser uma cultura que vem ganhando notoriedade, Kendall (1999, p. 262) lembra que "o significado de nerd ainda é um terreno em evolução e, possivelmente, contestação". Nesse sentido, torna-se então fundamental estudar as construções de sentidos sobre esta cultura (seus estilos de vida, aparência física e modos de viver), com o intuito de averiguar os seus discursos e a presença (ou não) de estereótipos que, segundo Freire Filho (2005) se caracterizam pelas construções simbólicas naturalizadas e disseminadas pelos meios de comunicação.

Sabendo também que as identidades são formadas através de pontos em comum, indagamos o fato de que muitas vezes não compartilham de passados similares, nem mesmo questões biológicas e/ou geográficas. Porém, estas identificações são adquiridas de alguma forma. Levanta-se, então, a questão midiática, pois, para Kellner (2001), a cultura veiculada pela mídia fornece materiais para que as pessoas moldem suas identidades, como é o caso dos nerds.

A origem do termo nerd é imprecisa, porém Santos (2014) e Lacombe (2012) traçam um breve histórico da palavra. De acordo com as autoras, ela teve sua origem no livro If I Ran the $Z o o^{2}$, de 1950, escrito pelo norte-americano Theodor Seuss Geisel. No livro, Gerald é uma criança que, após uma visita ao zoológico, não se impressiona com os animais existentes. Resolvendo então imaginar animais diversos para seu próprio zoo, ele inventa uma criatura a qual ele apelidou de nerd, caracterizando-a por ser um animal antipático e indiferente aos outros animais, sendo extremamente quieto. Outra teoria levantada pelas autoras fala que o termo teria origem nas faculdades americanas, onde os jovens que saíam para as festas e acabavam bêbados eram chamados de Drunks (bêbado em inglês) e os que ficavam em suas casas estudando eram vistos como não-bêbados, os Knurds (bêbado ao contrário). Com o tempo, a letra "k" acabou

Tradução do autor: Se eu dirigisse um zoológico. 
caindo em desuso, restando apenas a sigla nurd (nerd nos dias atuais).

Então, nos primórdios da definição deste estilo de vida, a definição do nerd ficou conhecida por representar imagens de jovens pouco populares, sem traquejo social e êxito amoroso, normalmente associado às escolas e universidades estadunidense (SANTOS, 2014). Pode-se pensar que estas características se referem apenas às primeiras definições dos indivíduos pertencentes a esta identidade, porém podemos perceber que elas acabaram se perpetuando no imaginário popular e na mídia mundial. Tomando como exemplo o meio audiovisual, e dentro dele as produções cinematográficas, cita-se a obra "Vingança dos nerds". Lacombe (2012, p. 2) classifica este filme como exageradamente estereotipado. Segundo ela, "foi um dos primeiros produtos midiáticos de grande repercussão a retratar a forma de vida e convívio com esse grupo que estava começando a surgir mais fortemente" (LACOMBE, 2012, p.2). Ainda de acordo om essa autora, o filme incluiu este termo pela primeira vez nos cinemas. Por isso, faz-se importante verificar se as características sobre o jovem nerd apresentadas no surgimento da representação sobre esta identidade ainda se fazem presentes.

Saindo do meio cinematográfico e focando no meio televisivo para ilustrar o objeto deste artigo (identidade nerd), aborda-se a série The big bang theory que, por muitos, é a mais lembrada quando se fala na temática desse grupo. Yokote (2014, p. 14) fala que a série "é interessante como um todo para se explorar diversas características atribuídas a estes sujeitos". Por ser uma série de sucesso mundial, The big Bang Theory é objeto de estudos de muitos pesquisadores que abordam a temática nerd. Santos (2014, p. 42) comenta que

\begin{abstract}
A série The Big Bang Theory, apesar de ter ajudado amplamente a popularizar a cultura nerd nos dias atuais, está longe de ser uma unanimidade. Há quem se incomode com o tom exageradamente esquisito dos personagens e com o roteiro que apenas menciona referências pop, dando mais atenção à inaptidão social dos personagens principais. [...] os nerds na série não fazem as piadas, eles são a piada. Também chama atenção o fato de um programa de TV que se apoia em referências da cultura pop/ nerd fazer tanto sucesso com audiências teoricamente não-nerds, o que também pode indicar um processo de fusão entre a cultura nerd e a cultura popular massiva, cada vez mais inseparáveis.
\end{abstract}

Após alguns exemplos de como o nerd é representado na mídia e a contextualização sobre o surgimento do termo, percebe-se que "nas representações audiovisuais surgiu o estereótipo que se consagrou no imaginário popular: as roupas fora de moda, o jeito desengonçado e tímido, os enormes óculos de grau" (SANTOS, 2014, p. 23). Lacombe (2012, p. 5) ressalta, então, que os indivíduos são apresentados nos meios de comunicação "através de uma ótica americanizada, constituído por jovens brancos e de classe média alta". Para Santos (2014), foram os jogos e filmes de super-heróis que auxiliaram no crescimento desta cultura em nossa sociedade. Nesse sentido, torna-se fundamental observar qual a construção midiática do estilo de vida nerd e analisar as narrativas e os discursos que construíram esta figura.

As representações midiáticas, em suma, devem repensar a forma como estas minorias são representadas na grande mídia. É importante que apresentem os traços referentes às diversas culturas presentes na sociedade de forma o mais próximo do real, não importando sobre 
qual grupo se está falando. No entanto, o controle de grupos hegemônicos promove a difusão de rótulos e estigmas (FREIRE FILHO, 2005).

\section{O Homem-Aranha}

Por ser um personagem popular, desde sua criação, a figura de Peter Parker é conhecida por várias gerações. Acompanhando sua popularidade, os estúdios Sony Pictures produziram adaptações de suas narrativas, cuja sinopse oficial conta a história de Peter Parker (Tobey Maguire), um jovem estudioso que vive com seus tios, Ben (Cliff Robertson) e May (Rosemary Harris). Desde que seus pais faleceram, Peter tem dificuldade de se relacionar com seus colegas, por ser tímido e por eles o considerarem um nerd. Porém, um acidente inesperado faz com que uma aranha modificada geneticamente pique Peter e, a partir de então, seu corpo é quimicamente alterado, fazendo com que desenvolva superpoderes.

Segundo seus criadores, a série Spider-Man abriu um novo território ao apresentar Peter Parker, o estudante por detrás da identidade secreta do Homem-Aranha, com as suas "auto-obsessões com a rejeição, inadaptações e solidão, algo com que os leitores mais jovens podiam se identificar" " ${ }^{3}$. Esta afirmação levanta a teoria de que os produtos midiáticos carregam consigo traços, como os objetos "em cena", ângulos, estilos de vida e principalmente personagens, os quais geram identificação com o público consumidor, em uma tentativa de transformar os produtos midiáticos em um ritual de "projeção-identificação" (GUBERNIKOFF, 2009, p. 70).

Desse modo, elegemos a análise textual de Casetti e Chio (1999) como percurso metodológico devido à possibilidade de analisar o material simbólico (signos, símbolos e figuras) de um produto em relação a seus componentes específicos, o que produz diferentes efeitos de sentido. Assim, pretendemos analisar o filme por meio de duas categorias propostas pro Casetti e Chio (1999):

a) Sujeitos: é possível abordar os fatores que contribuem para a caracterização do personagem, como sua aparência física, seus gostos pessoais, seus modos comportamentais, suas relações com outros personagens e seu traquejo social e amoroso;

b) Cena: serão analisados os elementos técnicos, os quais dizem respeito à elaboração das cenas como planos, cortes de câmera, transições etc.

Por utilizar o cinema para apresentar a história do herói, torna-se válido admitir que muitas pessoas enxergam nos conteúdos midiáticos (sejam eles transmitidos pela televisão, rádio, jornal e/ou cinema) pontos de referência para a vida cotidiana. É o que constatamos em Jodelet (2002) quando, ao falar sobre as representações, sugere que as mídias abordam em suas temáticas a verossimilhança, ou seja, buscam aproximar-se do mundo real. Desse modo, a escolha das cenas analisadas se deu a partir de um exercício empírico de contato com o material de análise, buscando apurar nosso olhar de pesquisa em pontos de virada na narrativa. Assim,

3 Disponível em: <http://aminoapps.com/page/comics-portugues/9179862/homem-aranha>. Acesso em: 24 abr. 2017. 
selecionamos as cenas que se mostraram mais relevantes para a investigação que propomos e que contribuíssem, portanto, para a compreensão da representação da identidade nerd no filme Homem-Aranha.

Passando para a análise em si, levam-se em consideração as teorias das representações midiáticas e como elas, nas palavras de Jodelet (2002), fornecem referências a serem seguidas e incorporadas pela sociedade, disseminando significados no imaginário comum. Como mostrado na figura 1, vemos o personagem Peter Parker, em que é possível verificar o uso de óculos, o cabelo num penteado tradicional (para o lado); é homem, de etnia branca, os olhos são azuis, e utiliza roupas confortáveis, porém pouco estilosas e em cores neutras. Observa-se que identidade nerd também se refere ao modo como os sujeitos se vestem e, para Santos (2014) usar esse tipo de vestimenta, é, de modo geral, uma característica deste grupo de indivíduos. Percebe-se então um padrão compartilhado por esta identidade, os quais podem influenciar os modos de agir dos indivíduos (ORTIZ, 2015).

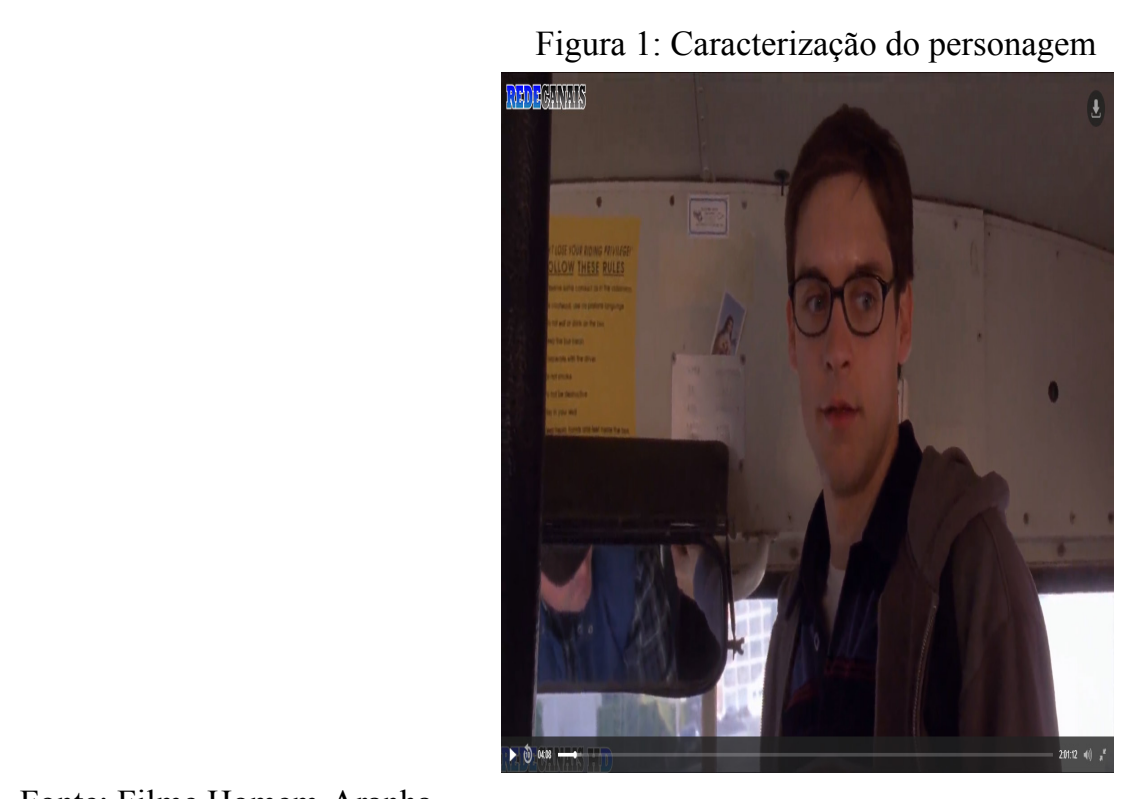

Fonte: Filme Homem-Aranha

A caracterização do personagem é bastante peculiar. Em uma reportagem a respeito dessa tribo no site "Tecnologia e Cinema", é explicitado que, nas produções cinematográficas, os nerds seriam os indivíduos que utilizam roupas em tons neutros,

\footnotetext{
óculos, cabelo repartido e cheio de gel, que gosta de ficção científica, de estudar, detesta assistir e praticar esportes, adora RPGs, vídeo-games e histórias em quadrinhos (HQs). Geralmente é muito tímido e antisocial. Vive sozinho e menosprezado pelos amigos. Tipicamente rotulado de virgem (BICCA, 2017 p. 288).
}

Como observado na figura anterior, essas características são facilmente reconhecidas na maneira como se faz a apresentação do personagem Peter Parker. A representação destes significados, para Jodelet (2002), configura a noção de realidade que as mídias constroem. Outro fato a se destacar é que, no decorrer da trama, ele nutre um amor pela personagem Mary Jane 
(Kirsten Dunst), porém não demonstra coragem para se declarar, conforme exemplificado pela figura 2, em que o personagem a assiste entrar no carro de outro garoto enquanto ele ensaia um modo de falar de seus sentimentos para a jovem. Essa cena, segundo Galvão (2009), relaciona-se ao fato de que os nerds são lembrados pela timidez e falta de autoconfiança, ocasionando modos desajeitados de agir.

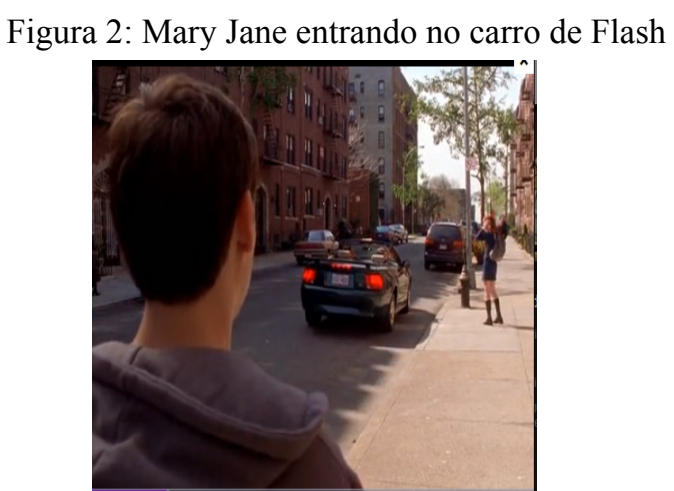

Fonte: Homem-Aranha

Outra característica das representações desta identidade é o fato de que seus indivíduos recorrentemente apresentam sua vida ligada a algum equipamento tecnológico, no caso de Peter, uma câmera fotográfica, como evidenciado pela figura 3.

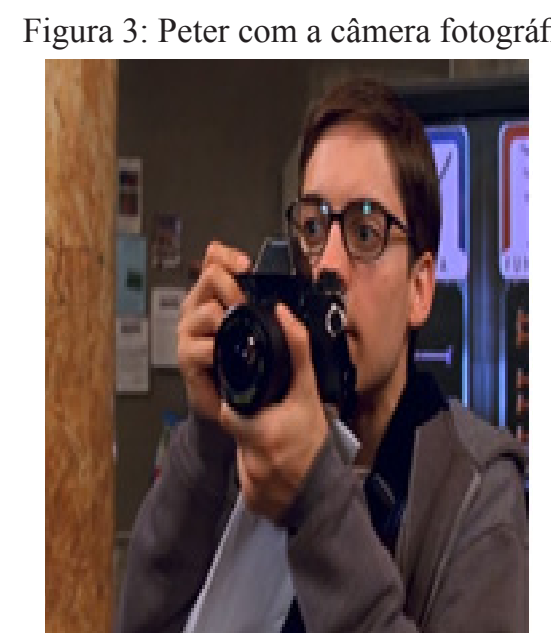

Fonte: Homem-Aranha

A presença da câmera fotográfica evidencia a paixão que Peter tem pela arte de fotografar e a afinidade que possui com a tecnologia. Para Maffesoli (2010), a noção de pertencimento à identidade nerd seria evidenciada pelo uso de artefatos tecnológicos, neste caso, a câmera fotográfica, pelo grau de conhecimento e pelas formas de se divertir com filmes de ficção científica, histórias em quadrinho, seriados de TV, jogos, entre outros artefatos culturais. Assim, esta característica sobre o indivíduo nerd está presente na figura 3, em que o personagem aparece com uma câmera fotográfica. Além disso, no decorrer do filme não são raras as cenas em que 
este recurso é utilizado.

As narrativas audiovisuais são compostas por diversos recursos que contribuem para seu entendimento. De modo simplicista e geral, pode-se citar os elementos que compõem seu próprio nome, como as palavras áudio e visual, que se tratam de como um conjunto de "linguagem-visual-sonora, em que as três matrizes se articulam para produzir um discurso narrativo" (GERBASE, 2003, p. 290). Sendo compostas por um conjunto de trilhas, diálogos e outros recursos sonoros agregados aos conteúdos imagéticos, onde estes correlacionam-se e auxiliam para estruturar as histórias. Estes elementos, encarados como partes dos textos, tornam-se fundamentais para se verificar todas as significações presentes nos filmes.

Ao observar o filme Homem-Aranha de 2002, percebemos que a primeira imagem do personagem aparece aos 3 minutos e 3 segundos. Nesta cena, ele é apresentado correndo para pegar o ônibus, enquanto todos seus colegas e o motorista riem de sua situação e não o deixam embarcar. Vale mencionar que a cena é elaborada em um plano plongée 4 , ressaltando a inferioridade dele em relação aos demais (figura 4). Este tipo de recurso imagético quando encarado por um viés semiótico, de acordo com Beividas (1983), colabora para um cenário de subjugação de um personagem.

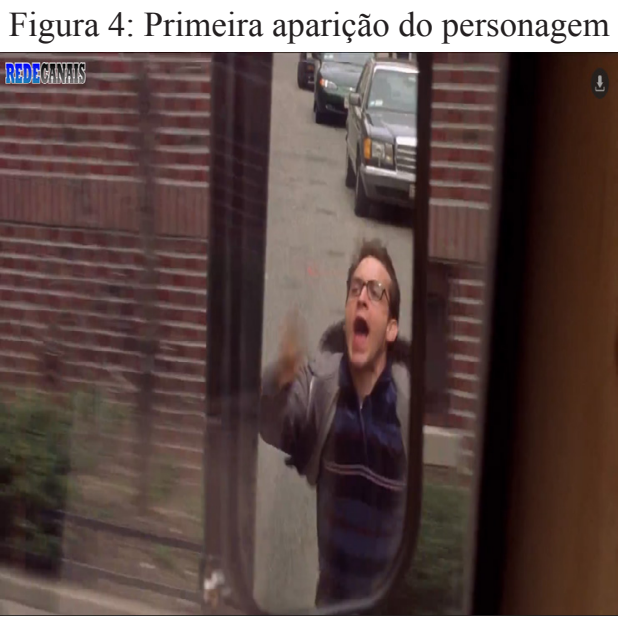

Fonte: Filme Homem-Aranha

Quando ele finalmente consegue embarcar, seus colegas relutam em deixá-lo sentar ao lado, evidenciando a falta de traquejo social do personagem, até mesmo a falta de amigos. Essa questão é levantada por Galvão (2009), que explica que os nerds, de modo geral, seriam indivíduos que nutrem grande fascínio pelos estudos ou com uma inteligência acima da média, porém, possuem certa dificuldade em relacionar-se socialmente, como nos é mostrado nesta sequência, pois a maioria dos personagens (ou todos eles) demonstram uma espécie de repulsa ao protagonista.

Figura 5: Personagem após cair

4 Quando a câmera está acima do nível dos olhos. 


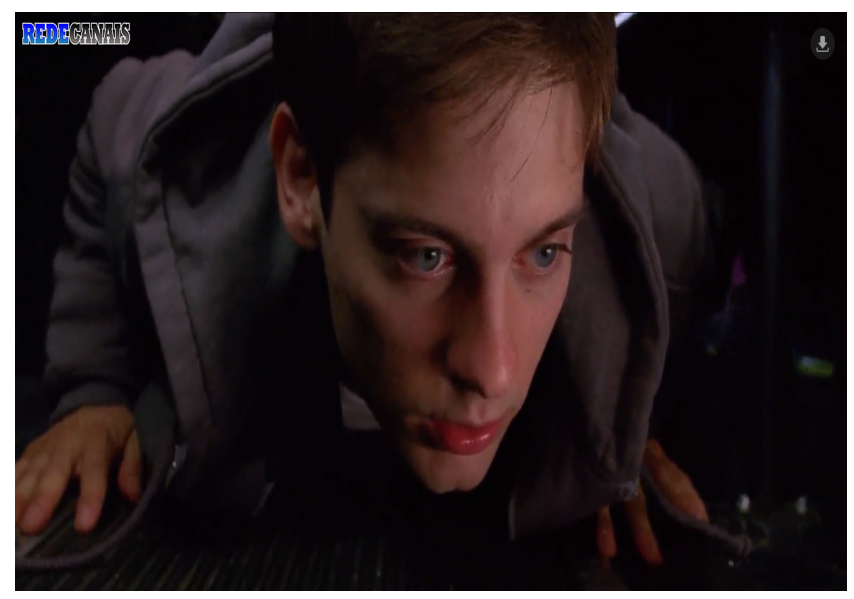

Fonte: Filme Homem-Aranha

Os primeiros dez minutos do filme são os mais significativos quando se fala na estruturação do personagem. Já aos 6 minutos, a turma do $3^{\circ}$ ano do ensino médio é mostrada em uma visita ao Departamento de Ciências da Universidade de Colúmbia. Neste momento, mais personagens são apresentados, como Harry Osborn - melhor amigo do protagonista - e, em 7 minutos e 24 segundos, mais uma vez a figura de Flash aparece importunando o herói com empurrões.

Observa-se aqui o fato de Flash ser maior que Peter, que o encara abaixo da linha dos olhos. Além disso, ele é posto em destaque no quadro, fazendo com que Peter pareça estar acuado em relação aos demais (figura 6).

Figura 6: Frame da cena do laboratório de Columbia

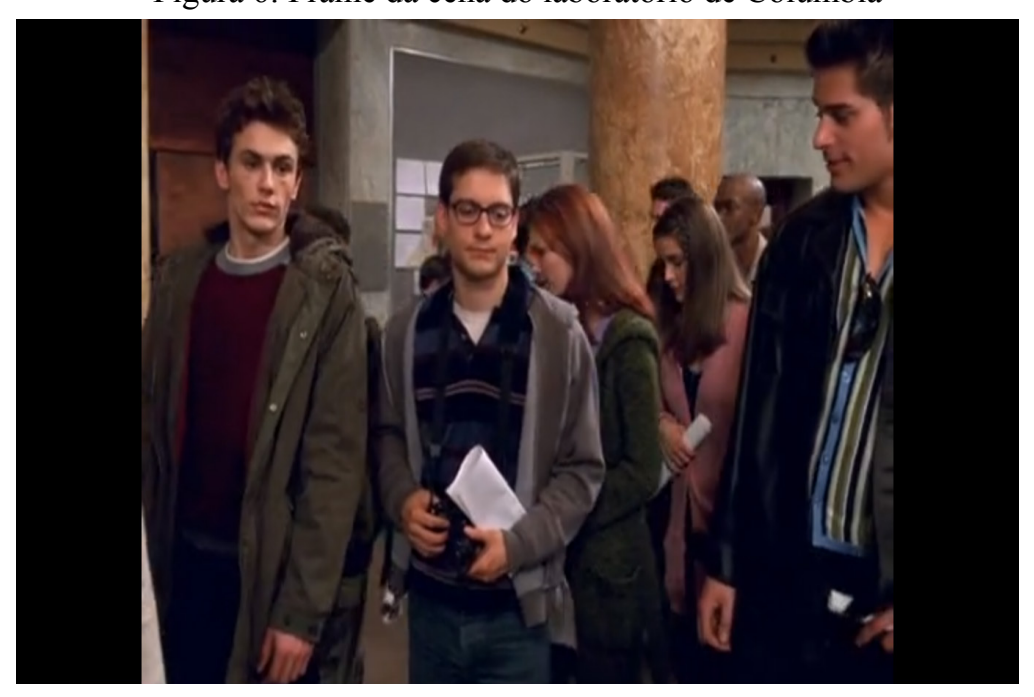

Fonte: Homem-Aranha

Um ponto de virada essencial à narrativa do filme ocorre aos 10 minutos e 24 segundos. Nesta cena, o personagem é picado por uma aranha geneticamente modificada, dando-lhe habilidades sobre-humanas, como: força, capacidade de escalar paredes, de lançar teias super-resistentes pelos punhos. Além disso, Peter também passa a ter um sexto sentido, chamado no filme de "sentido aranha", um conjunto de reflexos que o alertam para ameaças iminentes. A partir 
deste momento, ele assume duas personagens: a de super-herói e a de Peter Parker. Vale ressaltar que, neste ponto, o ângulo da câmera muda para um contraplonge $e^{5}$, evidenciando o empoderamento do personagem, que passara a incorporar o Homem-Aranha. Este tipo de cena bastante recorrente significa, para Miranda (2015, p. 16), que ser Peter Parker era uma fase que deixa de existir no momento em que é picado pela aranha geneticamente modificada (figura 7). Portanto, deixaria de ser apenas alguém nerd para assumir uma outra identidade, a de super-herói.

Figura 7: Peter é atacado pela aranha modificada

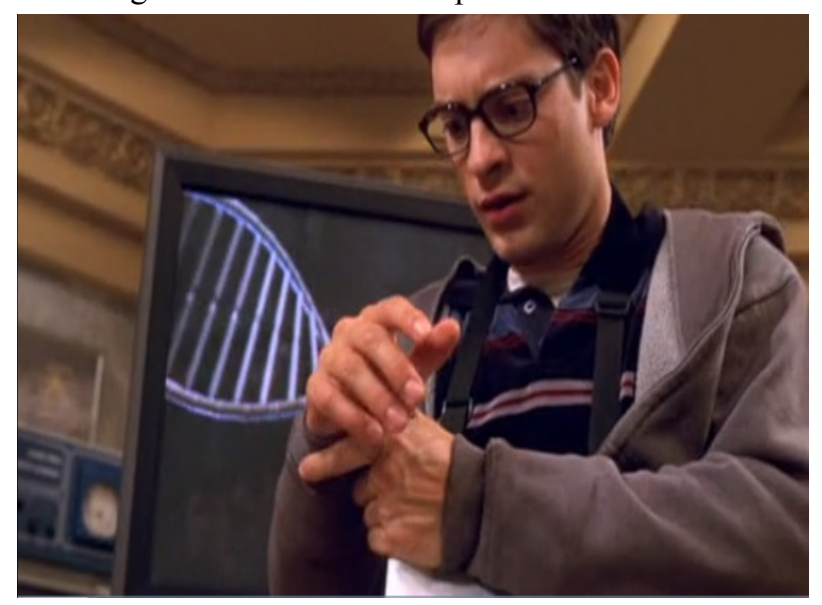

Fonte: Homem-Aranha

Passado o "susto" de ser picado pelo inseto, o protagonista vai à aula e, aos 22 minutos do filme, vemos o interesse amoroso do herói - Mary Jane Watson - indo em direção a ele no horário de almoço da escola. Porém, ao se aproximar, ela passa sem ao menos trocar um olhar com Peter Parker (figura 8). Percebe-se assim, que ele não tem muito êxito com ela. Outro ponto importante a se destacar nesta cena é o fato de ele estar sentado, de costas para o observador, e ela em pé, de frente para quem está assistindo ao filme, imprimindo, novamente, inferioridade ao personagem principal.

5 Quando a câmera está abaixo do nível dos olhos. 


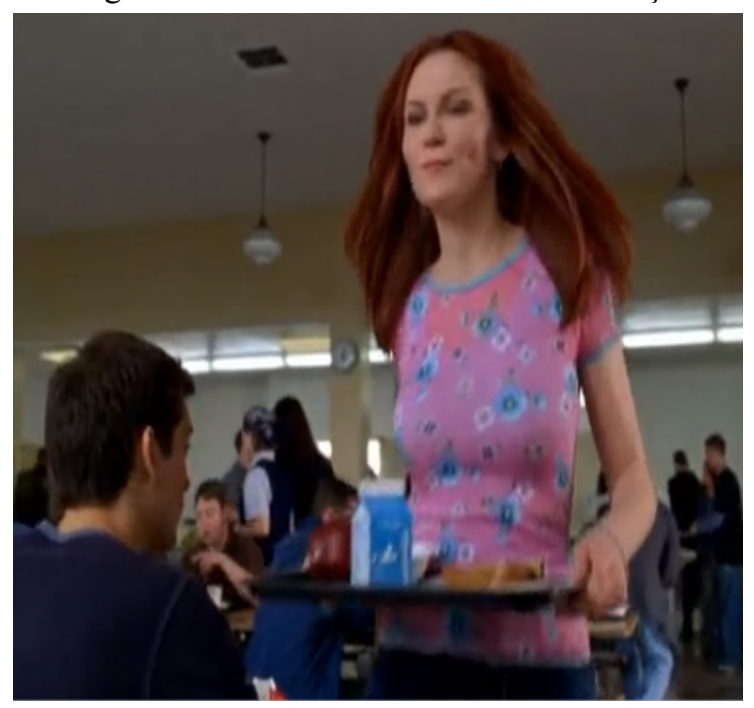

Fonte: Homem-Aranha

Após análise e entendimento dos elementos cenográficos, percebeu-se que o uso diversificado de ângulos, planos e situações contribuem, de alguma maneira, para que os elementos subjetivos elaborados no processo de produção fílmica sejam decodificados de maneira semelhante ao modo como foram idealizados, ou seja, os sentidos das mensagens se justificam no decorrer das cenas. Esta decodificação revela-se pelas audiências e evidencia o importante papel das representações na construção e manutenção das identidades. Como abordado anteriormente, Hall (2016) ainda salienta que estes significados acabam naturalizando-se devido ao fato de que circulam de forma rápida e abrangente.

No caso deste filme, a imagem do jovem nerd como alguém inferior e motivo de zombarias é tratada de forma clara e muito explorada, pois é vasto o número de vezes em que há a utilização de enquadramentos e expressões - linguagem, como quer Hall (1997) - que colaboram para que o telespectador tenha uma visão pejorativa do personagem. É esta representação do personagem que muda, após ele receber os poderes de aranha, indicando um ponto de virada na trama. Por fim, salienta-se que estudar as representações no meio midiático contribui para identificar e questionar os fatores que influenciam os modos de vida dos indivíduos, sendo esta uma das principais características dos Estudos Culturais.

\section{Considerações finais}

Durante a análise dos sujeitos foi possível verificar que Peter Parker, do filme Homem-Aranha de 2002, não é considerado uma pessoa popular, tampouco atraente em seu modo de se vestir ou em seu comportamento. Percebeu-se então que, passados 18 anos desde a primeira aparição da figura dos nerds no meio cinematográfico (1984 com "Vingança dos nerds"), o tratamento dado a ele sofreu poucas alterações, pois ainda estamos falando do meio escolar e de jovens de etnia branca sem êxito amoroso e social. Sobre o Homem-Aranha, nota-se deter- 
minado empoderamento a partir do ponto em que o personagem adquire superpoderes, porém trata-se de uma outra identidade, a de herói. A persona Peter Parker continua com as mesmas características desde o início do filme.

Nota-se, de acordo com Beahm (2011), que as produções centradas em nerds trazem em suas tramas o interesse amoroso do protagonista por uma garota vista como popular dentro do ambiente escolar, como é o caso de Homem-Aranha ao retratar a relação entre Mary Jane e Peter Parker. Porém, isto é tratado de forma humorística e, devido à timidez do protagonista, a jovem apenas o vê como amigo. Para tais constrangimentos, Beahm (2011, p. 9) fala que a presença de nerds nas produções serve para que os telespectadores riam deles e "não com eles".

Um aspecto a se destacar, não somente no filme em estudo, mas na maioria das produções, é a presença de personagens nerds de etnia branca, pertencentes ao gênero masculino e, como observado, todos eles são apaixonados por garotas. Assim, a figura do nerd no meio audiovisual silencia ou exclui o fato de também existirem mulheres e negros que se identificam com esta identidade e também nerds pertencentes ao público $L G B T Q I A P+{ }^{6}$.

Desta forma, salienta-se que o filme Homem-Aranha produzido em 2002 reafirma as características gerais sobre a identidade nerd presente em outras mídias - típico adolescente, inteligente, mas que não tem êxito na vida pessoal e é motivo de chacota. Essa representação caricata, portanto, acaba por reafirmar estereótipos e, assim silenciar outras características presentes nesse amplo grupo. Pode-se dizer que, de acordo com os três aspectos da cultura (HALL, 1997), o audiovisual analisado assume o papel indutivo. No tocante às questões relacionadas à identidade nerd, ele induz os(as) telespectadores(as) a aceitar, mesmo que de forma inconsciente, esta representação e modos de pensar sobre os nerds.

\section{Referências}

AMINO APPS. Homem-Aranha. Disponível em: <http://aminoapps.com/page/comicsportugues/9179862/homem-aranha $>$. Acesso em 24 de abril de 2017.

BEAHM, George. Big Bang - a teoria. São Paulo: Universo dos Livros, 2011.

BEIVIDAS, Waldir. O sentido e a forma na estrutura do signo. Alfa, São Paulo, v. 27, p. 09-22, 1983.

BICCA, Angela Dillmann Nunes, et al. Identidades Nerd/Geek na web: um estudo sobre pedagogias culturais e culturas juvenis. Conjectura: Filos. Caxias do Sul, v.18. n.1, p. 87-104, jan./abr. 2013.

BICCA, A.; CUNHA, A.; ESTEVE, L. Uma pedagogia cultural internáutica ensinando sobre jovens nerds/geeks. Textura. ULBRA, v. 19, p. 259-281, 2017.

CASETTI, Francesco; CHIO, Frederico di. Análisis de la televisión: instrumentos, métodos y

6 Sigla que significa lésbicas, gays, bissexuais, transexuais, queers, intersexuais, assexuados, panse- 
prácticas de investigación. Barcelona: Paidós, 1999.

CUCHE, Denys. A noção de cultura nas ciências sociais. Bauru: EDUSC, 2002.

FRANÇA, Vera; SIMÕES, Paula. Curso básico de Teorias da Comunicação. Belo Horizonte: Autêntica, 2017.

FREIREFILHO, João. Força de expressão: construção, consumo e contestação das representações midiáticas das minorias. Revista Famecos, Porto Alegre, nº 28, dezembro, 2005.

GALVÃO, Danielle Pini. Os nerds ganham poder e invadem a TV. Intr@ ciência. Guarujá, v. 1, n. 1, 2009.

GERBASE, Carlos. Impactos das tecnologias digitais na narrativa cinematográfica. Porto Alegre: EDIPUCRS, 2003.

GUBERNIKOFF, Giselle. A imagem: representação da mulher no cinema. Conexão. Caxias do Sul, v. 8, n. 15, p. 65-77, jan./jun. 2009.

HALL, Stuart. A centralidade da cultura: notas sobre as revoluções culturais do nosso tempo. Educação \& realidade, v. 22, n. 2, p. 15-46, jul./dez.1997.

. A identidade cultural na pós-modernidade. Rio de Janeiro: DP\&A, 2006.

Cultura e Representação. Rio de Janeiro: Apicuri, 2016.

HENRIQUES, Mariana Nogueira. Identidade feminina gaúcha: representações de gênero nos programas regionais Bah!. 2016. Dissertação (Mestrado em Comunicação) - Universidade Federal de Santa Maria, Santa Maria, 2016.

JODELET, Denise. Representações sociais: um domínio em expansão. In: JODELET, Denise (Org.). As Representações sociais. Rio de Janeiro: Eduerj, 2002.

KATZ, Hagai. Gramsci, hegemonia, e as redes da sociedade civil global. Redes. Barcelona, v. 12, n. 2, jun. 2007. Disponível em: <http://revista-redes.rediris.es/pdf-vol12/Vol12_2.pdf $>$ Acesso em: 20 de jan. 2018.

KELLNER, Douglas. A cultura da mídia. São Paulo: EDUSC, 2001.

KENDALL, Lori. Nerd nation: images of nerds in US popular culture. In: International Journal of Cultural Studies, 1999.

LACOMBE, Ana Carolina Ruas. O mundo é dos nerds: A representação midiática dos jovens deslocados no Brasil. Anagrama. São Paulo, v. 5, n. 4, jun./set. 2012. Disponível em: <https:// www.revistas.usp.br/anagrama/article/view/35653/38373> Acesso em: 10 de dez. 2017.

MAFFESOLI, Michel. O tempo das tribos. Rio de Janeiro: Forense Universitária, 2010.

MAZZOTTI, Alda Judith Alves. A abordagem estrutural das representações sociais. Revista Psicologia da Educação, São Paulo, n. 14-15, p. 17-37, 2002.

MIRANDA, Kirk Douglas Guedes de. O nicho como organização efêmera: uma análise sobre 
a comunicação e o comportamento dos nerds com relação a consumo, diversidade e ativismo. 2015. Monografia (Curso de Comunicação Organizacional) - Universidade de Brasília, Brasília, 2015.

O HOMEM-ARANHA. Direção de Sam Raimi. Produção de Sony Pictures. EUA: Columbia Pictures, 2002. (121 min).

OMELETE. A criação do Homem-Aranha nos quadrinhos. 2012. Disponível em: https:// www.omelete.com.br/homem-aranha/homem-aranha/a-criacao-do-homem-aranha $>$ Acesso em 2 de dezembro de 2017.

ORTIZ, Renato. Universalismo e diversidade: contradições da modernidade - mundo. São Paulo: Boitempo, 2015.

SANTOS, Patrícia Matos. O NERD VIROU COOL: consumo, estilo de vida e identidade em uma cultura juvenil em ascensão. 2014. Dissertação (Mestrado em Comunicação) Universidade Federal Fluminense, Rio de Janeiro, 2014.

WILLIAMS, Raymond. Cultura. Rio de Janeiro: Paz e Terra, 1992.

YOKOTE, Guilherme Kazuo Lopes. O mundo dos nerds: imagens, consumo e interação. 2014. Dissertação (Mestrado em Antropologia Social) - Universidade de São Paulo, São Paulo, 2014.

ZUBARAN, Maria Angélica; WORTMANN, Maria Lúcia; KIRCHOF, Edgar Roberto. Stuart Hall e as questões étnico-raciais no Brasil: Cultura, representações e identidades. Projeto História: Revista do Programa de Estudos Pós-Graduados de História, São Paulo, n. 56, p. 9-38, out. 2016. Disponível em: <https://revistas.pucsp.br/index.php/revph/article/ view/25714>. Acesso em: 20 ago. 2018.

Recebido em: 15/01/2018

Aceito em: 26/09/2018 